\title{
Desenvolvimento do senso numérico em crianças de um 10 ano do ensino fundamental
}

Marina de Souza Bortolucci ${ }^{1}$

Maria Auxiliadora Bueno Andrade Megid ${ }^{2}$

\section{Resumo}

Este artigo tem como objetivo analisar o desenvolvimento do senso numérico em um 10 ano do Ensino Fundamental, a partir do uso do jogo Forma Dez. Entendemos senso numérico como uma forma personalizada de lidar com os números e as operações e que seu desenvolvimento é perceptível pela maneira como cada um estabelece relações numéricas e apresenta estratégias de cálculo. A metodologia utilizada é de natureza interventiva, caracterizada como pesquisa da própria prática. Para a análise, foram escritas narrativas a partir das videogravações do jogo desenvolvido com a turma. O jogo revelou-se uma prática que pode colaborar para o estabelecimento de relações numéricas, contribuindo para o desenvolvimento do senso numérico. No entanto, as mediações de qualidade do professor são fundamentais.

Palavras-chave: Educação Matemática; Formação de Professores; Senso Numérico.

\section{Development of the numerical sense of a 1st year of elementary school}

\section{Abstract}

This paper aims to reflect on the contributions of To Form 10 game in the development of the numerical sense of a 1st year of Elementary School. We understand numerical sense as a personalized way of dealing with numbers and operations, and its development is noticeable by the way each one establishes numerical relationships and calculation strategies. The research methodology was qualitative, of an interventional nature, characterized as research of the practice itself. For the analysis, narratives were written based on the video recordings of the game developed with the class. The game proved to be a practice that can collaborate for the establishment of numerical relations, contributing to the development of the numerical sense, but mediations of quality of the teacher are fundamental.

Keywords: Mathematics Education; Teacher Education; Number Sense.

\section{Introdução}

Este artigo traz resultados da dissertação de Mestrado da primeira autora, sob orientação da segunda autora. Apresentamos um excerto da pesquisa, que corresponde à análise do jogo "Forma Dez" desenvolvido com um grupo de seis crianças, na qual tivemos por objetivo verificar como essas desenvolvem seu senso numérico, na interação com outras e a mediação da professora, durante a utilização de um jogo. O jogo foi aplicado com toda a turma, mas

\footnotetext{
1 PUC-Campinas, Campinas/SP. bsaniram@yahoo.com.br

2 PUC-Campinas, Campinas/SP. doramegid@gmail.com
} 
selecionamos apenas um grupo para análise nesse artigo.

As questões norteadoras da pesquisa foram: como crianças de um 10 ano do Ensino Fundamental, ao serem instigadas a ampliar o senso numérico, significam propostas pedagógicas envolvendo números? De que maneira as mediações realizadas pela professora-pesquisadora afetam esse desenvolvimento?

Tais questões estão imbricadas no objetivo geral da pesquisa, que foi analisar, em uma turma de 1으 ano do Ensino Fundamental, os avanços no desenvolvimento do senso numérico nas crianças, a partir da proposta de práticas relacionadas ao tema e das mediações da professora que atendam aos diferentes conhecimentos presentes nesse grupo. Buscamos analisar os indícios do avanço na aprendizagem do senso numérico nas crianças da turma, observando suas estratégias e caminhos percorridos nesse processo, a partir das mediações realizadas pela professora-pesquisadora, identificando quais foram as contribuições e limitações presentes no processo.

A pesquisa foi desenvolvida em um 1으 ano do Ensino Fundamental de uma escola da rede municipal de Campinas, turma na qual a pesquisadora atuou como docente no ano letivo de 2019. Tendo em vista os objetivos da pesquisa, pretendeu-se analisar a aprendizagem do senso numérico das crianças, além de observar as mudanças na prática pedagógica da professorapesquisadora e, portanto, constituiu-se em uma pesquisa da própria prática.

A metodologia desenvolvida, de natureza interventiva (TEIXEIRA; MEGID NETO, 2017), teve a professora-pesquisadora atuando ativamente, e não apenas como uma observadora passiva.

A pesquisa qualitativa possui uma gama de possibilidades e, dentre elas, optou-se para esta pesquisa a de natureza interventiva, a qual Damiani et al. $(2013$, p.58) definem da seguinte maneira

[...] são investigações que envolvem o planejamento e a implementação de interferências (mudanças, inovações) - destinadas a produzir avanços, melhorias, nos processos de aprendizagem dos sujeitos que delas participam e a posterior avaliação dos efeitos dessas interferências.

Tem a finalidade de contribuir para a resolução de problemas práticos, envolve planejamento e implementação de uma interferência e a avaliação de seus efeitos (DAMIANI et 
al., 2013), coerente, portanto, com os objetivos pretendidos para esta pesquisa.

Teixeira e Megid Neto (2017) indicam, como uma das modalidades de pesquisas de natureza interventiva, aquela sobre a própria prática. Afirmam que, nesse tipo de pesquisa "o foco investigativo reside na mudança de prática do professor-pesquisador e não sobre o produto didático elaborado" (p.1070).

Lima e Nacarato (2009, p.243) revelam que a pesquisa da própria prática pode trazer importantes contribuições à educação, defendendo que

[...] a pesquisa do(a)s professore(a)s da escola básica pode contribuir para que se venha a compreender quais conhecimentos são mobilizados na ação pedagógica e como eles são (re)significados; consequentemente, pode também contribuir para a pesquisa acadêmica e para a gestão de políticas públicas, bem como pode transformar esse(a)s professor(e/as) em consumidor(es) mais críticos das pesquisas acadêmicas.

As autoras destacam as seguintes razões em favor da pesquisa da própria prática: possibilidade de o professor assumir-se como protagonista do seu desenvolvimento profissional - trata-se de um processo de (auto)formação -, mobiliza a atuação do professor como transformador da cultura escolar, além de fornecer elementos que levam à melhor compreensão dos problemas educacionais.

Ponte (2004), ao tratar da relevância da pesquisa da própria prática, destaca que a investigação se inicia com a identificação de um problema relevante de sua prática profissional. Defende que a pesquisa da própria prática deve ser considerada um gênero de investigação, com suas características próprias.

O autor ressalta a colaboração como ponto fundamental desse tipo de pesquisa, principalmente do papel dos grupos colaborativos, pois "há muitas coisas que o investigador sozinho não consegue ver, das quais o professor sozinho também não se apercebe, mas que os dois em colaboração podem compreender e transformar" (PONTE, 2004, p.22).

É importante ressaltar que essa pesquisa nasceu a partir das inquietações geradas por estudos e discussões em um grupo colaborativo, que se constituiu em importante espaço de trocas e reflexões para a professora-pesquisadora, coautora deste artigo.

Pesquisar a própria prática é um grande desafio, além de relevante na jornada docente, uma 
vez que exige colocar-se em posição de análise profunda, olhar para si mesmo e para as relações estabelecidas com os outros no processo de ensino e aprendizagem, de maneira a detectar pontos fundamentais que, muitas vezes, passam despercebidos na prática como professor.

\section{Senso numérico: perspectiva teórica}

Sabemos que os números estão presentes no nosso cotidiano e apresentam diferentes funções, seja como localizador, quantificador, ordenador, identificador, entre outras atribuições. É função da escola possibilitar a apropriação desse universo numérico de maneira sistematizada, de forma que tal conhecimento faça sentido para a criança, tornando-a capaz de estabelecer relações por si mesma, para que não assimile esse campo apenas como técnicas a serem memorizadas.

Em nossa sociedade estamos cercados por diversas informações numéricas, na leitura de gráficos, tabelas, porcentagens, quantidades representadas por números decimais, entre outros. Para lidar com todas essas representações, tornando-as compreensíveis, é fundamental um bom desenvolvimento do senso numérico (MORAIS; SERRAZINA, 2013).

Castro e Rodrigues (2008, p.118) destacam que a Matemática está longe de ser um simples apanhado de regras, fatos e fórmulas, trata-se de importante instrumento necessário para a compreensão, análise e intervenção dos sujeitos na sociedade em que vivemos. Para as autoras, o senso numérico "é uma componente chave da literacia matemática, na medida em que contribui para o desenvolvimento de pensamento flexível, elemento base da capacidade de resolver problemas".

Também sobre a aprendizagem que envolva número, Lorenzato $(2011$, p.35) aponta que o

[...] número está no plano do abstrato e, como tal, só o próprio aprendiz poderá consegui-lo, realizá-lo, adquiri-lo, percebê-lo ou construí-lo, pois o número não está no objeto (como cor, forma, dimensão, posição), mas encontra-se na mente de quem percebe ou cria relações entre objetos, eventos, situações ou ações. Como esse processo se dá, ainda não sabemos; o que sabemos é que podemos propiciar situações que permitam a construção desse conceito.

Assim, basear o ensino da Matemática apenas no reconhecimento de numerais, é o 
mesmo que esperar que a criança escreva apenas conhecendo as letras do alfabeto, sem Ihes atribuir qualquer sentido. Essa aprendizagem é necessária, porém não deve ser o único, nem o principal foco do docente em seu trabalho. Lorenzato (2011) destaca que o símbolo (numeral) é a representação de uma ideia (número) e que o domínio do primeiro não significa, necessariamente, a aprendizagem do segundo.

Tendo em vista a complexidade que envolve a aprendizagem do número e suas relações, para esta pesquisa decidimos nos debruçar sobre o estudo do senso numérico. Afinal: qual o papel da escola, mais propriamente do 1ㅇ ano do Ensino Fundamental, no desenvolvimento do senso numérico dos alunos?

Destacamos que, na literatura especializada, encontramos os termos "senso numérico" e "sentido do número" como sinônimos. São expressões mais adequadas aos estudos desse ensino e aprendizagem, definidos como a compreensão genérica que cada um possui sobre números e operações (CEBOLA, 2007). Para nossa pesquisa, optamos pelo uso de "senso numérico", mais comumente encontrado nas publicações brasileiras.

Van de Walle (2009) afirma que o termo senso numérico ficou popular no final dos anos 1980, mas suas definições são um pouco vagas. O autor afirma que o senso numérico se desenvolve a partir da exploração dos números em diferentes contextos e através do estabelecimento de relações que não sejam limitadas aos algoritmos tradicionais.

A origem do termo senso numérico não é precisa, embora seja claro que surgiu, em grande parte, pelo desejo de substituir a palavra "numeramento" por outra que não estivesse associada com uma visão conservadora e estéril das necessidades matemáticas (MCINTOSH; REYS; REYS, 1992).

Para Cebola (2007, p.226), o senso numérico é "algo impreciso, pessoal e personalizado, que está relacionado com as ideias que cada um foi estabelecendo sobre os números e as operações e que nem sempre é fácil de descrever". Com um senso numérico bem desenvolvido, o sujeito identifica qual estratégia lhe é mais confortável para utilizar diante de uma situação problema, podendo se mostrar, muitas vezes, completamente distinto de caminhos escolhidos por outras pessoas. Isso vai muito além da identificação do cálculo que necessita ser feito para a resolução do problema. O aluno, a partir das relações que estabelece entre os números, realiza o cálculo com procedimentos pessoais e consegue perceber se o resultado encontrado é 
plausível ou não.

Para os autores que se dedicam a esse estudo, apesar de ser difícil de se definir, ressaltam que é possível reconhecer a existência do senso numérico em contextos práticos, principalmente em situações nas quais o sujeito faz uso eficiente do cálculo mental. Trata-se de "algo altamente personalizado e relaciona-se com as ideias sobre os números que desenvolvemos e com o modo como essas ideias se relacionam entre si e com outras ideias" (CASTRO; RODRIGUES, 2008, p.118).

Destacamos que o cálculo mental flexível, a estimativa de quantidades numéricas e os julgamentos quantitativos são, portanto, importantes indícios de um senso numérico bem desenvolvido (SERRAZINA, 2012). Na mesma direção, Morais e Serrazina (2013, p.54-55) destacam, também, as seguintes características de um senso numérico desenvolvido:

a) o trabalho com números e não com dígitos, uma vez que os números são vistos como um todo, mantendo o seu valor; b) a utilização de propriedades de cálculos elementares e de relações numéricas; c) apoiado num bom conhecimento dos números e num profundo conhecimento de factos numéricos básicos com números até 20 e até 100; e d) podendo ser utilizadas notas intermediárias de acordo com a situação, mas, principalmente, calculando mentalmente.

Cabe a reflexão: a escola tem oportunizado situações nas quais seus alunos se deparem com problemas, jogos ou propostas de ensino em geral que favoreçam o despertar e o desenvolvimento dessas características? Pautar o ensino nessa perspectiva é possibilitar ao aluno a compreensão de que há múltiplas estratégias possíveis na resolução de problemas matemáticos, diversas estratégias podem ser utilizadas para cálculos e que, mais importante que o acerto, é ser capaz de identificar se a resposta encontrada faz sentido (CEBOLA, 2007).

Morais (2011) afirma que o senso numérico não é uma entidade finita, que se tem ou não. Trata-se de um processo que se desenvolve e amadurece com experiência e conhecimento, não apenas no período escolar, mas por toda a vida.

Para além do conhecimento que cada um possui sobre os números e operações, o senso numérico "relaciona-se também com a aptidão e a escolha de cada um na utilização desse conhecimento de modo ágil, crítico e no desenvolvimento de estratégias cada vez mais eficientes de cálculo" (MORAIS; SERRAZINA, 2013, p.53). 
Uma prática pedagógica voltada para o desenvolvimento do senso numérico é aquela que valoriza e estimula as diferentes formas de pensar do aluno sobre o número e as operações, permitindo-lhe refletir sobre esses processos e desenvolver autonomia para traçar suas estratégias, sem esperar a validação do professor. É fundamental que os alunos possam comunicar oralmente seus raciocínios nas aulas de Matemática, o que contribui significativamente para sua compreensão e o auxilia na organização do próprio pensamento e na reflexão de suas respostas (SERRAZINA, 2012).

Van de Walle (2009) destaca, em seus estudos, que a criança desenvolve o senso numérico durante todo o seu percurso escolar, ao elaborar métodos flexíveis para calcular e realizar estimativas. Por isso, o ensino deve oportunizar que a criança reflita sobre o número desde a sua chegada nos anos iniciais do Ensino Fundamental. Isso contribuirá, significativamente, para sua aprendizagem nessa área, garantindo uma base sólida para os diversos conhecimentos que terá contato ao longo da sua escolarização.

Porém, o que algumas vezes se observa, nos anos iniciais do Ensino Fundamental, é um investimento no ensino da Matemática em contagens de conjuntos, reconhecimento de algarismos, escritas numéricas descontextualizadas e um salto para o ensino dos algoritmos convencionais - reforçando a concepção já ultrapassada de que ao ensinar a técnica das quatro operações a escola está cumprindo com seu papel nesse campo do ensino.

O algoritmo convencional é um conhecimento historicamente construído e, portanto, é direito da criança aprendê-lo, para que opte ou não pelo seu uso. Destacamos, no entanto, que deveria tratar-se de uma possibilidade. O que vemos, muitas vezes, são práticas em sala de aula que enfatizam apenas o uso do algoritmo tradicionalmente utilizado nas escolas, ensinado pela repetição de procedimentos, desprovido de compreensão de seus significados, por vezes levando a criança a pensar ser este o único procedimento possível para se alcançar um resultado correto na resolução de uma tarefa ou de um problema. Segue o aluno - e suas famílias acreditando que se não se faz continhas, não se está aprendendo Matemática.

Trata-se de uma perspectiva de ensino preocupante, pois embora muitas crianças pequenas demonstrem estratégias criativas e, por vezes, eficientes para lidar com números, a atenção dada aos algoritmos formais no ensino escolar pode levar ao desencorajamento do uso de métodos pessoais (MCINTOSH; REYS; REYS, 1992). Sobre essa questão, os autores destacam 
que, conforme o conhecimento técnico da matemática dos alunos vai se ampliando, suas estratégias diminuem, pois dão preferência aos algoritmos tradicionais, que podem ser realizados mecanicamente. Muitas vezes, ao serem questionados sobre a razoabilidade do cálculo, a reação do aluno é fazer o cálculo novamente, usando a mesma técnica inicial.

Realizar o cálculo novamente não é o problema em questão - muitas vezes, é um comportamento reforçado pela própria escola - mas, sobretudo, a falta de raciocínio reflexivo da criança acerca do resultado obtido, demonstrando dificuldades, por exemplo, em estimar ou perceber se o valor encontrado é razoável, se faz sentido para a resolução do problema proposto.

Serrazina $(2012$, p.16) destaca que estudos sobre o desenvolvimento do senso numérico mostram que

[...] o ensino que o promove é aquele que se foca na compreensão dos conceitos, criando para isso um ambiente de sala de aula onde é encorajada a comunicação, a exploração, e o raciocínio, nomeadamente promovendo a discussão de várias estratégias na resolução de tarefas.

Em vista da fundamentação teórica apresentada, é possível perceber que muitos teóricos do campo da Educação Matemática dedicaram-se à pesquisa do senso numérico, evidenciaram a importância do seu desenvolvimento para a aprendizagem matemática significativa e, sobretudo, apontaram para a necessidade de maiores estudos sobre a temática.

Esta pesquisa, portanto, destaca a importância de se analisar, de forma sistematizada, práticas de ensino que contribuam efetivamente para esse desenvolvimento do senso numérico em crianças nos anos iniciais do Ensino Fundamental, propondo-se a observar indícios dos caminhos percorridos nessa construção, através da pesquisa da prática docente, permitindo aproximações entre as teorias destacadas com as práticas em sala de aula.

\section{O jogo "forma dez" e o desenvolvimento do senso numérico}

Com o intuito de atingir os objetivos elencados nesta pesquisa, e considerando as diversas necessidades e conhecimentos apresentados pela turma durante o ano letivo, foram escolhidas e desenvolvidas cinco tarefas: (i) desafio das bolinhas, (ii) dez nos dados, (iii) jogo forma dez, (iv) jogo da base dois e (v) atividade canudos na sapateira. Para este artigo, apresentamos as 
reflexões realizadas a partir do jogo "Forma Dez".

Destacamos que as propostas foram aplicadas mais de uma vez com as crianças, pois compreendemos que elas precisam de várias oportunidades para se apropriarem das regras dos jogos, se envolverem e criarem estratégias próprias, o que demanda tempo. As atividades foram filmadas e, posteriormente, transcritas pela professora-pesquisadora na forma de narrativas, utilizadas como material de análise para a pesquisa.

Os fios condutores da análise das narrativas foram a observação e a reflexão, sobretudo, sobre os indícios de desenvolvimento do senso numérico nas crianças, as interações significativas que ocorreram entre elas, principalmente no compartilhamento de estratégias, e as mediações realizadas pela professora-pesquisadora.

Optamos pela escrita narrativa, pois possibilita a reflexão sobre o momento vivido, sobre a própria experiência. Contribui com a reconstrução da trajetória percorrida, dando novos significados ao vivido. Trabalhar com essa perspectiva tem a finalidade de levar a pessoa tornarse visível por ela mesma, envolvendo-a em um processo de reflexão-ação: "trata-se, sim, de um diálogo entre a prática vivida e as construções teóricas formuladas nesta e sobre estas vivências" (CUNHA, 1997, p.190).

Defendemos que essa forma de escrita propicia ao professor ser pesquisador de sua própria prática, levando-o a atingir importantes reflexões, como os propósitos indicados por Ibiapina (2008, p.67): “a ênfase na atividade reflexiva está no ato de pensar, de examinar com senso crítico e sistemático a própria atividade prática".

Para o jogo "Forma dez", as crianças foram divididas em quatro grupos com seis crianças cada. A divisão dos alunos em grupos foi feita pela professora-pesquisadora, de maneira que todos ficassem heterogêneos em relação ao saber matemático. Para este artigo, selecionamos a narrativa e análise do segundo grupo a jogar. Esclarecemos que, por tratar-se da narrativa da professora-pesquisadora a respeito do vivido durante as atividades e da produção dos dados, a escrita se dará na 1a pessoa do singular.

O jogo "Forma dez" fazia parte do meu acervo de jogos matemáticos há alguns anos, tendo sido utilizado, várias vezes, com outras turmas com as quais trabalhei. Trata-se de uma adaptação do jogo da memória. Cada grupo recebe cartas de 1 a 9, que devem ser dispostas no centro do grupo, viradas para baixo. A cada jogada, a criança deve virar duas cartas e caso a soma 
resulte em dez, ela fica com as cartas e pode jogar mais uma vez. Vence quem conseguir mais cartas. Destaco que os nomes das crianças foram substituídos por nomes fictícios para que seu anonimato fosse configurado.

Após jogar "Forma dez" com um grupo, logo no princípio do período da aula, chamei os alunos Rafael, Amanda, Mariana, Pablo, Natan e Giovana para participar. As crianças se mostraram muito empolgadas para jogar. Já com as cartas distribuídas no centro do grupo, comecei perguntando quem se lembrava das regras.

Rafael: Eu lembro! 5 mais 5 dá 10!

Prof.a.: Opa! Está certo, mas vamos com calma, vamos às regras primeiro! O que tem que fazer nesse jogo?

Amanda: Joga um de cada vez...

Prof.. : Sim... Mas o que tem que fazer, gente?

Mariana: Tem que virar um número e formar 10 !

Prof. - Tem que pegar 2 cartinhas daqui do meio e ver se a soma dá 10!

Amanda começou o jogo, virou as cartas 6 e 4 . Perguntei se a soma daria 10. Ela, após contar nos dedos, disse que o resultado daria 8. Solicitei que ela refizesse e as crianças começaram a dar dicas.

Giovana: Guarda o número maior na cabeça e junta o outro.

Após refazer a contagem nos dedos, Amanda disse que a soma era 10 e jogou mais uma vez. Dessa vez tirou os números 5 e 2: fazendo sobrecontagem a partir do 5 , chegou ao resultado 7 e passou a vez. Pablo jogou e virou as cartas 6 e 8 .

Amanda: Já passou! - provavelmente observando que ambos os números eram maiores que 5.

Prof.. : Deixa ele pensar...

Ao analisar esse episódio, percebi que poderia ter pedido para Amanda explicar seu raciocínio para os colegas, dando oportunidades que eles incorporassem outras estratégias de estimativa. Nem sempre chegar ao resultado se faz necessário. As estimativas são muito úteis ao raciocínio humano e pouco consideradas no ambiente escolar.

Seguindo o jogo, Pablo indicou que viraria mais uma carta da mesa. Intervi, e disse que eram apenas as duas cartas que ele já havia virado. Perguntei se a soma daria 10. 
Rafael: Guarda o 8 na cabeça!

Prof. : Conta, Pablo! - Pablo era muito quieto, sempre adotava a postura de esperar que alguém fizesse por ele, o que provavelmente interferia em sua aprendizagem.

Rafael, sem paciência, começou a fazer a contagem, mas pedi que ele tivesse calma com o amigo.

Pablo: 9?

Prof.ạ: 9? Não! Dá mais! Vamos lá, você consegue!

Giovana: Guarda o 8 na cabeça e coloca 6 nos dedos!

Amanda pegou nas mãos de Pablo para colocar o 6 e ele não contestou. As crianças começaram a fazer a sobrecontagem a partir do 8, como Giovana sugeriu, e Amanda foi indicando um dedo da mão de Pablo para cada número, chegando ao resultado 14, mas provavelmente essa contagem não fez sentido para ele.

Em sua vez, Natan virou a carta 8.

Amanda: Precisa de mais 2! Eu já sei onde está o 2! - demonstrando que estava atenta ao jogo.

Natan tirou a carta 2 e, mesmo após a afirmação de Amanda, realizou a contagem nos dedos para verificar se dava 10. Jogou outra vez e pegou as cartas 3 e 5 . Ele, então, colocou esses números nos dedos e realizou a contagem um a um, chegando ao resultado 8 , sem conseguir reconhecer o número, apenas observando os dedos erguidos.

Giovana, na sua vez, virou as cartas 5 e 1 . Mesmo ela sugerindo, a todo instante, aos colegas que guardassem o número na cabeça e acrescentassem o outro, na sua vez, optou por colocar o 5 em uma mão e o 1 na outra. Ela começou a contar e Amanda a interrompeu.

Amanda: Giovana, você sabe quanto dá! Não precisa contar! - ela mostrou para Giovana o 6 nas suas mãos, indicando que já conheciam essa representação e não era necessário realizar a contagem um a um para determiná-la.

Mesmo assim, sem compreender o que disse Amanda, Giovana voltou a fazer a contagem um a um para determinar a resposta. Também, pude notar que ela não compreendeu que o resultado da soma $5+1$ corresponde ao número seguinte do 5 , ou seja, o 6 .

Mariana virou as cartas 5 e 5 . Ela exclamou que daria 10, mas também fez a contagem nas mãos para confirmar, ao que foi interpelada por Rafael: Nem precisa contar, Mariana! 
Essas falas recorrentes dos alunos sobre a não necessidade de contar sinaliza uma compreensão numérica mais avançada. Interessante salientar que é comum encontrar em todas as turmas escolares essa diversidade de saberes e compreensões entre os alunos. No entanto, tal característica prevalece ainda mais no 10 ano do Ensino Fundamental, exigindo um olhar atento do professor sobre as necessidades da turma a fim de propor mediações.

Em sua próxima jogada, Mariana virou as cartas 9 e 1. Ela começou a realizar a contagem nos dedos e os colegas, impacientes, queriam que Mariana fizesse de outras formas. Afinal, ela também não percebeu que o resultado era o sucessor do 9. Pedi para terem paciência com a colega e deixassem que pensasse como preferisse. Isso a desconcentrou, pois quando chegou ao 9 em sua contagem, esqueceu de acrescentar o 1 e disse que não daria.

Prof. : Calma, coloca o 9 na mão... Agora coloca mais 1 - ela ergueu o dedo que faltava. Prof. . : Quanto deu?

Mariana: 10! Diferentemente de Giovana, Mariana percebeu, na segunda ação relativa à soma de suas cartas, a quantidade de dedos, sem precisar realizar a contagem 1 a 1.

Mariana jogou mais uma vez e virou as cartas 5 e 5 . Dessa vez ela não recorreu à contagem, já identificando prontamente que a soma totalizou 10. Na próxima jogada, Mariana tirou 7 e 9. Logo foi inquirida por Amanda:

Já passou... Ela percebeu que os números eram muito altos para somarem 10

Mariana começou a fazer a contagem nos dedos, mas percebeu que não daria certo, pois não havia dedos suficientes. É interessante observar a necessidade das crianças de chegar ao resultado do cálculo. Isso, talvez, decorresse das minhas mediações, pois poderiam pensar, como uma possível estratégia para esse jogo, que se os dedos das mãos não eram suficientes para somar determinados números, o resultado necessariamente passaria de 10 , resultado almejado para pontuar no jogo.

Infelizmente, em vez de fazer essa reflexão com Mariana, pedi que Amanda a ajudasse e, então, ela colocou 9 dedos em suas mãos, enquanto Mariana colocou 7 dedos nas suas. Assim, juntas, fizeram a contagem chegando ao resultado 16. Mais uma vez, reforcei a contagem como estratégia. Destaco, mais uma vez, que poderia recorrer a diversas outras possibilidades, inclusive valorizando estratégias de outras crianças do grupo. Seria interessante, também, estimular que Amanda argumentasse como ela sabia que passaria de 10 ou, ainda, ter 
perguntado qual carta seria o par do 9 para totalizar 10, que a própria Mariana tirou na rodada anterior.

Van de Walle (2009, p.144) aborda a importância de desenvolver as relações numéricas:

Um desenvolvimento rico e completo das relações numéricas é um fundamento crítico para o domínio de fatos numéricos básicos. Sem as relações numéricas, os fatos podem apenas ser memorizados mecanicamente. Com uma compreensão numérica, os fatos fundamentais da adição e subtração são relativamente simples.

Apesar de o jogo possibilitar que as crianças memorizem os fatos básicos, boas mediações são fundamentais para favorecer o estabelecimento das relações numéricas. Através da escrita da narrativa pude perceber que minhas intervenções apenas reforçaram a contagem como um caminho para chegar à solução, o que me fez repensar a minha prática.

Seguindo o jogo, Rafael virou a carta 2 e demorou para escolher outra.

Prof. : Vamos lá, Rafael!

Rafael: Eu quero saber onde que está o 8! - demonstrando antecipar sua jogada, ao saber qual número deveria tirar para conseguir as cartas.

Prof. .. Está no começo do jogo... Vai ter que virar na sorte... Não lembro se o 8 já saiu...

Rafael tirou a carta 9 e começou a fazer a contagem.

Prof. ․: Mas... que número você falou que precisava?

Rafael: 8 !

Prof. : E foi o 8 que você virou?

Rafael: Não, porque eu queria saber onde que estava o 8...

Prof. . : Então... Essa carta que você virou vai dar 10?

Mesmo assim, Rafael fez a sobrecontagem, pois afirmou que queria saber quanto dava. Partiu do 9 e chegou na resposta 11. Poderia ter auxiliado Rafael a executar um cálculo mental, talvez propondo: se $2+8=10,2+9$ é 1 a mais, ou seja, 11 .

Ferreira (2008) destaca que as relações numéricas mais utilizadas pelos alunos no campo aditivo são dobros e quase dobros, no qual a partir de um cálculo conhecido de dobro é possível estabelecer relações do dobro mais 1 ou menos 1; utilizar a estrutura do 5 ou do 10, realizando ajustes nos números para facilitar o cálculo; fazer compensações, como por exemplo, 6 + $8=7+$ 
7 = 14; e utilizar fatos conhecidos. Conforme exemplifica a autora, se $6+8=14$, então $7+8$ deve ser $14+1=15$.

Possivelmente, algumas crianças já estabeleceram algumas dessas relações. Convidá-las a expor suas formas de pensar poderia auxiliar outros alunos a refletirem sobre os números e iniciarem essa compreensão.

Pablo virou as cartas 7 e 4 . Ajudei-o a realizar a sobrecontagem, pois, mais uma vez, demonstrou não ter nenhuma iniciativa. Acredito que Pablo necessite de outro tipo de intervenção, em outro momento, de forma individual, pois foi difícil perceber quais eram suas dificuldades naquele contexto, se estavam relacionadas à Matemática, à timidez, ou a ambas.

Passou a vez para Natan, que tirou as cartas 7 e 2. Ele tentou fazer a contagem nos dedos, mas se atrapalhou e não percebi que sua resposta foi que a soma seria 7. Apenas ao assistir à gravação, notei que ele passou a vez sem que ninguém fizesse qualquer intervenção na sua resposta. Me questionei, ao refletir sobre o ocorrido, se a minha presença do início ao fim em atividades em grupo não desencorajou a postura dos alunos de se sentirem responsáveis também pelo jogo. Conjeturando sobre essa questão, pensei que poderia me reportar mais ao grupo em vez de adotar uma fala direcionada à criança que estava jogando, perguntar aos demais se concordavam com o resultado ou com a estratégia adotada, se poderíamos seguir com o jogo ou não, compartilhando a responsabilidade com todos.

Mas, também entendo que a sala de aula, suas múltiplas demandas, composta por diferentes pessoas, com distintas inquietações, exige dos professores ações sobrenaturais. Ao mesmo tempo em que reflito e busco em mim as melhores atitudes para cada momento, é importante que perceba a limitação humana, as possibilidades de errar, de tropeçar, de não ser perfeita e de seguir adiante, buscando outros momentos para aperfeiçoar o que já é bem realizado.

Giovana virou as cartas 6 e 2. Ela começou a fazer a contagem nos dedos, mas demonstrou dificuldade, colocando números aleatórios nas mãos. Pedi para que levantasse primeiro seis dedos, mas mesmo assim ela se atrapalhou. Giovana repetira, sempre, para os colegas algumas dicas, como "guardar um número na cabeça". Porém, quando chegava sua vez de jogar e somar, demonstrava pouca habilidade com os números, tendo dificuldade até mesmo para fazer contagem de um em um com números baixos. Tentei outro recurso. 
Prof. : Quantos anos você tem?

Giovana: 6!

Prof. : E quando você quer mostrar quantos anos você tem, como você mostra na mão?

Giovana, então, levantou rapidamente 6 dedos. Interessante observar que ela não fez a relação do número que representava a sua idade com o 6 da carta escolhida, para ela pareciam coisas completamente diferentes. A representação dos 6 anos em seus dedos remetia ao nome de sua idade e não à quantidade de tempo vivido por ela. Isso demonstrou que ela precisava avançar em algumas compreensões mais básicas relacionadas aos números.

Falei, então, para que levantasse mais 2 dedos, o que fez corretamente. Perguntei quanto ficou no total. Giovana começou a fazer a contagem a partir do 1, mas não estabeleceu relação de ditar um número para cada dedo, chegando a um total que passava do 8 .

Prof. - . É um dedo porvez, um número por dedo! Com calma, vamos de novo! - reforçando a ideia de correspondência um a um.

Giovana levantou 6 dedos, em seguida levantou mais 2 e refez a contagem, dessa vez de forma correta, chegando ao resultado 8.

Em seguida, Mariana virou as cartas 7 e 1 . Fez a contagem de 1 em 1, colocando nos dedos até chegar no 8 . A situação "número +1 " foi recorrente nesse grupo e praticamente todas as crianças realizaram a contagem para resolver.

Natan tirou as cartas 9 e 2. Enquanto ele colocava os números nos dedos das mãos, Amanda afirmou que havia passado do 10. Natan se atrapalhou, pois sua estratégia não deu certo: não havia dedos suficientes! Amanda tentou ajudá-lo, mas ele ficou ainda mais confuso. Enquanto isso, Rafael, impaciente, fez a sobrecontagem.

Rafael: Olha! 9... 10, 11! - indicando que acrescentou 2 ao 9.

Natan persistiu em sua estratégia, apesar de manter-se confuso. Tentei auxiliar.

Prof. : Coloca 9 dedos. Ainda falta 1! Isso! Agora a Amanda vai te emprestar 2 dedos. Agora conta! - mais uma vez minha intervenção estava atrelada à contagem.

Natan fez a contagem e finalmente chegou à resposta 11 .

Mariana: Já passou! Se você tirasse 1... - Mariana demonstrou com suas intervenções estar refletindo sobre as jogadas dos colegas.

Giovana tirou 5 e 1. Ela levantou 5 dedos em uma mão e 1 na outra. Quando ela começou 
a contagem, Amanda a interrompeu.

Amanda: Giovana, você já fez!

Ela referia-se ao fato de que, na rodada anterior, Giovana necessitara levantar 6 dedos e que, apesar de ter relação com o número que representava sua idade, pareceu não fazer essa associação.

Rafael: Dá 6!

Prof. . : Deixa ela pensar, calma!

Giovana: 6! - após terminar a contagem 1 a 1.

Após outra rodada, era a vez de Giovana que virou as cartas 5 e 6. Mariana a aconselhou a guardar o 6 na cabeça. Enquanto isso, Giovana pensava e mexia com os dedos.

Giovana: 7 !

Amanda: 7 ? Não pode dar $7 .$.

Rafael: É 11, Giovana!

Prof. : Coloca 6 dedos na mão!

Amanda pegou nas mãos de Giovana para levantar os 6 dedos. Pedi que ela tivesse paciência com a colega e deixasse que ela colocasse do jeito dela. Falei, então, para Mariana levantar 5 dedos para que Giovana fizesse toda a contagem. Giovana contou apenas um dedo de sua mão e juntou com os de Mariana dando 6. Salientei que ela deixou de contar os dedos da outra mão e pedi para repetir o processo. Quando ela fez uma nova contagem, chegou na resposta 10. Percebi que Giovana queria chegar à resposta rapidamente, o que a atrapalhou, deixando-a nervosa, não conseguindo fazer correspondência 1 a 1 . Ela parecia necessitar avançar ainda em questões mais básicas da construção numérica, como a correspondência um a um. Sobre isso, Lorenzato (2011, p.94-95) afirma que

A correspondência é um processo mental fundamental para a construção dos conceitos de número e das quatro operações. Grande parte das dificuldades que as crianças apresentam, na aprendizagem inicial da aritmética, deve-se ao fato de elas não terem compreendido o processo de correspondência em toda sua abrangência.

Também fiquei em dúvida se Giovana estava nervosa por estar em um grupo, buscando apresentar um desempenho rápido como outros colegas. 
Mariana: Não! Você comeu 1 dedo, quando chegou no 9, você pulou esse dedo... Não é $10 !$

Giovana repetiu a contagem mais uma vez e, apesar de fazer a relação 1 a 1 no início, quando se aproximou do final, acelerou novamente, não fazendo a correspondência correta.

Prof. . : Olha, tem que ir devagar, falar um número para cada dedo, sem pressa. Deu 11, não pode pular nenhum dedo...

Em sua vez, Rafael virou a carta 2.

Rafael: Alguém pegou o 8? - perguntando para os colegas.

Falei que a carta 8 já havia aparecido. Então, ele escolheu outra carta, mas era um 9. Mesmo assim, Rafael fez a sobrecontagem, pois queria encontrar a resposta da soma: 11! Mais uma vez poderia ter partido da soma que Rafael já conhecia o resultado: se $8+2=10$, então $9+$ 2 é um a mais, ou seja, 11.

Combinei com a turma que iríamos encerrar o jogo naquele momento, pois logo começaria a aula de Arte, com outra professora. Assim, pedi que contassem quantos pares cada um havia conquistado até aquele momento. Amanda e Natan conseguiram 1 par cada um, Pablo, Giovana e Rafael não ficaram com nenhum e Mariana foi a vitoriosa, com 3 pares.

\section{Considerações finais}

Uma das reflexões proporcionadas pelo jogo "Forma Dez" com esse grupo de crianças refere-se às minhas dúvidas relacionadas ao momento certo de intervir, ou não, nas jogadas dos alunos. Meu objetivo foi tentar analisar qual estratégia as crianças utilizavam, interferindo o menos possível, em um primeiro momento, para conseguir perceber suas táticas de cálculo. Mas ao produzir a narrativa e me debruçar sobre a análise, percebi que, quase sempre, as minhas mediações direcionaram as crianças a utilizarem a contagem ou a sobrecontagem, em vez de estimulá-las a estabelecer relações numéricas e valorizar estratégias que apareceram recorrentemente.

Essas minhas intervenções, possivelmente, acabaram reforçando nas crianças a ideia de que seria preciso chegar a um resultado, mesmo percebendo que a soma passava de 10 , algo que chamou minha atenção no momento do jogo. Porém, não tive clareza, durante as 
intervenções, que eu estava de certa forma incentivando essa postura com as mediações adotadas.

Com o estudo dos referenciais teóricos pude refletir e perceber que, mais importante do que as crianças memorizarem os fatos básicos, seria incentivá-las a estabelecer relações entre os diferentes cálculos. Quem sabe perceber os dobros e seus antecessores ou sucessores.

Da mesma maneira, poderia ter feito mediações que, em vez de visarem o resultado da soma, questionassem qual número formaria o par correto para determinada carta, pois muitas vezes as crianças pareciam prever qual carta necessitavam. Mesmo ao virar um número diferente, acabavam recorrendo à contagem para conferir o resultado.

Outro ponto que chamou minha atenção foi o não reconhecimento, por algumas crianças, de números representados nos dedos das mãos. Um exemplo muito marcante ocorreu com a aluna Giovana, que teve dificuldades para reconhecer que havia levantado 6 dedos $(5+1)$, mesmo a colega Amanda chamando sua atenção para o fato de que não era necessário fazer a contagem, pois ela sabia que quantidade era aquela. Naquele momento, questionei quantos anos Giovana tinha e ela afirmou ter 6 . Na posterior análise, percebi que Giovana não conseguiu estabelecer relação entre essas duas situações: o 6 "quantidade" e o 6 "sua idade", revelando que ela precisava avançar em algumas aprendizagens relacionadas ao conceito de número, desenvolver o senso numérico em diferentes perspectivas. Essa aluna, quando fez a contagem dos dedos, também não estabeleceu relação um a um, pulando dedos ou contando mais rápido do que apontava para cada um, outra questão fundamental para a aprendizagem numérica.

Esse grupo se dividiu entre crianças que recorriam à contagem a todo momento e outras que afirmavam recorrentemente "não precisa contar!", seja porque possuíam a percepção da quantidade de dedos erguidos ou mesmo porque já tinham adquirido a habilidade de cálculos "número + 1". Foram recorrentes as ocasiões em que as crianças tiravam a carta 1 e outro número, cálculo simples de ser realizado. Porém, isso realmente se fazia tranquilo para as crianças que percebiam que o resultado seria o número seguinte. Esse aspecto também poderia ter sido explorado com o grupo, mas acabei reforçando o uso da contagem.

Outra característica desse grupo foi a necessidade de algumas crianças conferirem o resultado, mesmo sabendo que seria diferente de 10. Em um momento do jogo, questionei Rafael em razão de ele antecipar a carta de que necessitava (8). Porém, ao tirar a carta 9, 
começou a fazer a contagem. Quando indaguei a ele sobre a necessidade de tal contagem, ele afirmou saber que não daria 10, mas queria descobrir o resultado. Para isso, fez uma sobrecontagem bem-sucedida. Entretanto, eu poderia ter aproveitado aquele momento, e alguns outros que apareceram durante o jogo com circunstâncias análogas, para auxiliá-lo no avanço das relações em seus cálculos. Poderia, por exemplo, estabelecer diálogos como esse: se $2+8=10,2+9$ é um a mais, ou seja, 11 . Sobre isso, Ferreira $(2008$, p.146) destaca que

quando as relações são o foco, há muito menos factos para recordar pois as ideias fundamentais como a compensação, a inclusão hierárquica e a relação parte/todo entram em jogo. Também, se uma criança esquece uma resposta, ela tem uma maneira rápida de a alcançar.

Poderia, também, ter explorado a percepção de Amanda ao afirmar que a soma de números altos "passa de 10". De maneira recorrente, ela afirmou que ultrapassaria o 10, apenas batendo os olhos nas cartas viradas pelos colegas. Contudo, em nenhum momento eu a questionei sobre como ela pensou para chegar a essa conclusão. É fundamental oportunizar situações em que as crianças explicitem o seu modo de pensar. Suas exposições podem proporcionar aos colegas percepções que ainda não haviam formulado.

Acredito que, por todas as reflexões aqui elencadas, o jogo "Forma 10" se mostrou um bom instrumento para perceber as relações numéricas que as crianças conseguem ou não estabelecer. Tal prática de ensino pode contribuir para o desenvolvimento do senso numérico dos alunos ao propiciar o contato com fatos básicos da adição. Porém, é fundamental que as mediações do professor estejam direcionadas para o estabelecimento de relações numéricas, seja auxiliando nas interações entre os alunos ou mesmo despertando reflexões importantes para as crianças.

Na minha experiência pessoal, um dos maiores impactos da pesquisa foi perceber que ações que já havia desenvolvido com várias turmas, para que eu conseguisse alcançar os objetivos, necessitavam de reflexões relacionadas às mediações. Notar que, por vezes, essas mediações iam na contramão dos meus propósitos. Em vez de auxiliar no estabelecimento de relações numéricas, enfatizava o uso da contagem como estratégia, algo que eu gostaria que as crianças superassem gradativamente. Essa percepção só foi possível com o estudo aprofundado sobre o senso numérico proporcionado pela pesquisa, assunto fundamental aos professores dos 
anos iniciais e que, até então, tive poucas oportunidades de me debruçar.

Escrever as narrativas e me debruçar sobre suas análises propiciou momentos intensos de reflexões, que me permitiram revisitar o vivido, favorecendo a elaboração de um novo olhar sobre a minha prática, além de impulsionar a busca de maiores compreensões sobre a aprendizagem das crianças. A escolha pela escrita narrativa tem essa intenção: "ao mesmo tempo que o sujeito organiza suas ideias para o relato - quer escrito, quer oral - ele reconstrói sua experiência de forma reflexiva e, portanto, acaba fazendo uma autoanálise que lhe cria novas bases de compreensão de sua própria prática" (CUNHA, 1997, p.187).

Como encontrado em Larrosa (2002, p.21), "as palavras com que nomeamos o que somos, o que fazemos, o que pensamos, o que percebemos ou o que sentimos são mais do que simplesmente palavras". Colocar no papel a minha prática, para que outras pessoas lessem, causou uma imersão no vivido e favoreceu a análise do que queria transmitir, escolher quais palavras utilizar: será que as pessoas compreenderiam o que realmente estava se passando? Mas será que eu mesma compreendia essas narrativas? Afinal, cada vez que revisitei os episódios vividos, sobretudo após um estudo detalhado sobre o tema, meu olhar sobre os acontecimentos também foi mudando. Como propõe Larrosa (2002)

\begin{abstract}
A experiência, a possibilidade de que algo nos aconteça ou nos toque, requer um gesto de interrupção, um gesto que é quase impossível nos tempos que correm: requer parar para pensar, parar para olhar, parar para escutar, pensar mais devagar, olhar mais devagar, e escutar mais devagar; parar para sentir, sentir mais devagar, demorar-se nos detalhes suspender a opinião, suspender o juízo, suspender a vontade, suspender o automatismo da ação, cultivar a atenção e a delicadeza, abrir os olhos e os ouvidos, falar sobre o que nos acontece, aprender a lentidão, escutar aos outros, cultivar a arte do encontro, calar muito, ter paciência e dar-se tempo e espaço (LARROSA, 2002, p.19).
\end{abstract}

Senti e vivi todos esses aspectos trazidos por Larrosa (2002), as muitas certezas que nem sabia que tinha e que foram sendo colocadas em xeque, questionadas, repensadas, reorganizadas, transformadas!

Nesse sentido, a escolha da metodologia de pesquisa da própria prática trouxe importantes benefícios: colocou minhas ações pedagógicas em foco de análise, permitindo que enquanto professora-pesquisadora pudesse refletir sobre minhas ações, os meus erros e acertos. Para além disso, pensar sobre o tipo de mediação que se faz necessária para auxiliar no 
desenvolvimento do senso numérico das crianças do 10 ano do Ensino Fundamental.

Destaco, ainda, que para uma mediação de qualidade é fundamental que o professor perceba as múltiplas estratégias realizadas pelas crianças. Foi-me possível perceber que nem todas as mediações precisam partir do professor. Mostrou-me a importância de criar um ambiente no qual a turma se sinta à vontade para expor suas ideias, e que o professor terá como fundamental papel incentivar os próprios alunos a formularem e explicitarem seus pensamentos, contribuindo com todo o grupo.

É comum encontrar, em todos os anos escolares, a diversidade de saberes e compreensões entre os alunos, revelando uma heterogeneidade de conhecimentos e estratégias no grupo. Porém, no 1ำ ano do Ensino Fundamental, essa é uma característica ainda mais profunda e, por isso, exige do professor um olhar cuidadoso para que atenda todas as necessidades da turma ao propor mediações adequadas.

Foi com o desenvolvimento da pesquisa e o aprofundamento do estudo teórico que pude colocar em perspectiva minhas ações em sala de aula, refletindo sobre meus erros e limitações naquele momento. Mas, sobretudo, a escrita narrativa possibilitou que eu repensasse e propusesse possibilidades para superar esses desafios.

Prado, Ferreira e Fernandes (2011, p.145) destacam que as diferentes escritas narrativas são "gêneros discursivos privilegiados para que os educadores documentem o que fazem, o que pensam, o que pensam sobre o que fazem, assim como suas inquietações, dificuldades, conquistas, sua produção intelectual". Como já apontado anteriormente, esse movimento possibilita ao professor o reconhecimento da necessidade de analisar o que faz, reconhecer o que conhece e o que precisa conhecer. Com isso, fica claro o potencial da narrativa como recurso formativo para os professores:

Os educadores que têm assumido o desafio de escrever suas narrativas pedagógicas afirmam em atos a convicção de que, tal como professava Paulo Freire, um tanto de sonho e de utopia sempre pode se tornar realidade quando os problemas são encarados e, ao invés de nos paralisarem, mobilizam a ação, alimentam a reflexão, dão sentido ao movimento de ação-reflexão-ação. Fazem, esses profissionais, um bonito retrato do exercício do direito de inventar inéditos, de inventar a si, de inventar a nós mesmos (PRADO; FERREIRA; FERNANDES, 2011, p.146). 
Vale salientar que compreendo os limites das ações do professor. É impossível ter controle sobre tudo que ocorre com sua turma, principalmente sobre a aprendizagem dos alunos. A sala de aula possui múltiplas demandas, é composta por uma diversidade de pessoas, com diferentes necessidades. Além disso, o imprevisível está sempre presente. Em razão de tudo isso, o professor deve ter o compromisso com o avanço dos conhecimentos de seus alunos, além da responsabilidade de refletir sobre suas práticas e melhorá-las. Mas, é importante que perceba sua condição humana, portanto, falível, reconhecendo que os tropeços fazem parte de sua trajetória. Ao compreender isso pode, sobretudo, adotar uma postura investigativa e buscar momentos e situações para aperfeiçoar sua prática.

Diante do vivido, de todas as possibilidades de leituras e de aprofundamento nas reflexões da prática, percebo a necessidade de ampliar pesquisas relacionadas ao desenvolvimento do senso numérico, ainda mais, do trabalho com a Matemática nas primeiras etapas escolares, para que possamos estimular que as crianças elaborem estratégias de pensamento matemático, de interação com os pares nos trabalhos com essa disciplina. Tudo isso contribui para que se apropriem de estratégias próprias e que se sintam valorizadas pelas ações que utilizam.

\section{Referências}

CASTRO, J. P.; RODRIGUES, M. O sentido de número no início da aprendizagem. In: BROCARDO, J.; SERRAZINA, L.; ROCHA, I. (orgs.). O sentido do número: reflexões que entrecruzam teoria e prática. Lisboa: Escolar Editora, 2008. p.117-133.

CEBOLA, G. Do número ao sentido do número. In: PONTE, J. P. et al. (orgs.). Atividades de investigação na aprendizagem da matemática e na formação de professores. Lisboa: Secção de Educação e Matemática da Sociedade Portuguesa de Ciências da Educação, 2007, p.223-239.

CUNHA, M. I. Conta-me agora!: As narrativas como alternativas pedagógicas na pesquisa e no ensino. Rev. Fac. Educ., São Paulo, v.23, n.1-2, p.185-195, 1997. Disponível em:

http://www.scielo.br/scielo.php?script=sci_arttext\&pid=S0102-

25551997000100010\&lng=en\&nrm=iso. Acesso em: 02 ago. 2016.

DAMIANI, M. F. et al. Discutindo pesquisas do tipo intervenção pedagógica. Cadernos de Educação, Pelotas, v.45, n.45, p.57-67, 2013. Disponível em: https://periodicos.ufpel.edu.br/ojs2/index.php/caduc/article/view/3822. Acesso em: 30 out. 
2019.

FERREIRA, E. A adição e a subtracção no contexto do sentido de número. In: BROCARDO, J.; SERRAZINA, L.; ROCHA, I. (orgs.). O sentido do número: reflexões que entrecruzam teoria e prática Lisboa: Escolar Editora, 2008. p.135-157.

IBIAPINA, I. M. L. M. Pesquisa colaborativa: investigação, formação e produção de conhecimento. Brasília: Líder, 2008.

LARROSA, J. Notas sobre a experiência e o saber de experiência. Revista Brasileira de Educação, Rio de Janeiro, n.19, p.20-28, 2002. Disponível em:

https://www.scielo.br/scielo.php?pid=s1413-

24782002000100003\&script=sci_abstract\&tlng=pt. Acesso em 28 mar. 2020.

LIMA, C. N. M. F; NACARATO, A. M. A investigação da própria prática: mobilização e apropriação de saberes profissionais em Matemática. Educação em Revista, Belo Horizonte, v.25, n.2, p.241-266, ago. 2009. Disponível em: http://www.scielo.br/scielo.php?pid=S010246982009000200011\&script=sci_abstract\&tlng=pt. Acesso em: 21 ago. 2019.

LORENZATO, S. Educação infantil e percepção matemática. Campinas: Autores Associados, 2011.

MCINTOSH, A.; REYS, B. J.; REY, R. E. A proposed framework for examining basic number sense. For the Learning of Mathematics. FI M Publishing Association, British Columbia, v.12, n.3, p.844, 1992.

MORAIS, C. M. S. O cálculo mental na resolução de problemas: um estudo no 10 ano de escolaridade. 2011. 198f. Dissertação (Mestrado em Educação Matemática) - Instituto Politécnico de Lisboa, Lisboa, 2011.

MORAIS, C.; SERRAZINA, L. O cálculo mental na resolução de problemas de subtração. Quadrante, Lisboa, v.22, n.1, p.53-76, 2013. Disponível em: https://www.researchgate.net/publication/322357925_O_Calculo_Mental_na_Resolucao_de_ Problemas_de_Subtracao. Acesso em: 21 ago. 2020.

PONTE, J. P. Investigar a nossa própria prática: Uma estratégia de formação e de construção do conhecimento profissional. In: Castro, E.; Torre, E. (eds). Invertigación en educación matemática, Coruña, v.2, n.4, p.61-84, 2004. Disponível em http://www.educ.fc.ul.pt/docentes/jponte/docspt/04-Ponte-Corunha.pdf. Acesso em: 21 ago. 2019.

PRADO, G. V. T.; FERREIRA, C. R.; FERNANDES, C. H. Narrativa pedagógica e memoriais de formação: escrita dos profissionais da Educação? Revista Teias, v.12, n.26, p.143-153, 2011. Disponível em: https://www.epublicacoes.uerj.br/index.php/revistateias/article/view/24216/17195. Acesso em: 17 dez. 2020. 
SERRAZINA, M. L. O sentido do número no 10 ciclo: uma leitura de investigação. Boletim GEPEM, Rio de Janeiro, s/v, n.61, p.15-28, 2012. Disponível em:

http://r1.ufrrj.br/gepem/paginas/sumario/SumarioBoletimGEPEM_1ao71_5ab2018.pdf. Acesso em: 10 ago. 2020.

TEIXEIRA, M.; MEGID NETO, J. Uma proposta de tipologia para pesquisas de natureza Interventiva. Ciênc. Educ., Bauru, v.23, n.4, p.1055-1076, 2017. Disponível em:

http://www.scielo.br/pdf/ciedu/v23n4/1516-7313-ciedu-23-04-1055.pdf. Acesso em: 21 ago. 2019.

VAN DE WALLE, J. A. matemática no ensino fundamental: formação de professores e aplicação em sala de aula. Porto Alegre: Artmed, 2009.

Recebido em dezembro 2020.

Aprovado em novembro 2021. 